\title{
Large-Scale Influences on Summertime Extreme Precipitation in the Northeastern United States ${ }^{\mathscr{D}}$
}

\author{
Allison B. MARQuardt Collow \\ Universities Space Research Association, Columbia, and Goddard Earth Sciences Technology and Research, \\ and Global Modeling and Assimilation Office, NASA Goddard Space Flight Center, Greenbelt, Maryland \\ Michael G. Bosilovich AND RANDAL D. KOSTER \\ Global Modeling and Assimilation Office, NASA Goddard Space Flight Center, Greenbelt, Maryland
}

(Manuscript received 7 April 2016, in final form 23 August 2016)

\begin{abstract}
Observations indicate that over the last few decades there has been a statistically significant increase in precipitation in the northeastern United States and that this can be attributed to an increase in precipitation associated with extreme precipitation events. Here a state-of-the-art atmospheric reanalysis is used to examine such events in detail. Daily extreme precipitation events defined at the 75th and 95th percentile from gridded gauge observations are identified for a selected region within the Northeast. Atmospheric variables from the Modern-Era Retrospective Analysis for Research and Applications, version 2 (MERRA-2), are then composited during these events to illustrate the time evolution of associated synoptic structures, with a focus on vertically integrated water vapor fluxes, sea level pressure, and 500-hPa heights. Anomalies of these fields move into the region from the northwest, with stronger anomalies present in the 95th percentile case. Although previous studies show tropical cyclones are responsible for the most intense extreme precipitation events, only $10 \%$ of the events in this study are caused by tropical cyclones. On the other hand, extreme events resulting from cutoff low pressure systems have increased. The time period of the study was divided in half to determine how the mean composite has changed over time. An arc of lower sea level pressure along the East Coast and a change in the vertical profile of equivalent potential temperature suggest a possible increase in the frequency or intensity of synoptic-scale baroclinic disturbances.
\end{abstract}

\section{Introduction}

Observations indicate that extreme precipitation events have increased throughout the contiguous United States (CONUS), with the largest increase in the northeastern region of the country (Janssen et al. 2014; Melillo et al. 2014; Agel et al. 2015; Frei et al. 2015). Flooding associated with extreme precipitation events can result in economic losses and the loss of life, which highlights

Supplemental information related to this paper is available at the Journals Online website: http://dx.doi.org/10.1175/ JHM-D-16-0091.s1.

Corresponding author address: Allison B. Marquardt Collow, Global Modeling and Assimilation Office, NASA Goddard Space Flight Center, Code 610.1, 8800 Greenbelt Rd., Greenbelt, MD 20771.

E-mail: allison.collow@nasa.gov the need for a complete understanding of such events. An improved understanding of extreme precipitation events and how they will change in the future will help enable the precautions needed to protect society from such events, for example, through more accurate forecasts.

While it is quite possible that the increasing trend in extreme precipitation events will continue into the future, there is considerable uncertainty (IPCC 2013; Janssen et al. 2014). The frequency of extreme precipitation events in the Northeast varies by season, and this frequency has changed over time. Significant increases in precipitation in the Northeast have been documented in the fall and on an annual time scale (Kunkel et al. 2013), and a statistically significant increase in extreme precipitation events has been documented during the Northeast warm season (Frei et al. 2015). Many studies have shown that warmer air can hold more water vapor, thereby increasing extreme rainfall; however, the increase in extreme precipitation 
in the Northeast has been shown to exceed that dictated by the Clausius-Clapeyron relationship (Ivancic and Shaw 2016).

Trends in observed precipitation and extreme precipitation events in the northeastern United States are further complicated by various meteorological causes that differ in frequency depending on the season and region (Kunkel et al. 2012; Agel et al. 2015; Frei et al. 2015). Extreme precipitation events in the Northeast have been shown to be caused by extratropical cyclones, tropical cyclones, frontal systems, and mesoscale convective systems (Konrad 2001; Kunkel et al. 2012; Agel et al. 2015). Tropical cyclones tend to produce the most intense summer and fall extreme precipitation events in the region, whereas frontal systems are the most common cause for an extreme precipitation event during the summer and on an annual time scale (Konrad 2001; Kunkel et al. 2012); however, varying spatial domains and definitions of an extreme precipitation event produce a range of percentages of events caused by tropical cyclones (Barlow 2011; Kunkel et al. 2012; Agel et al. 2015). Fronts have been shown to be responsible for the vast majority of annual precipitation in major storm-track regions and $76 \%$ of annual extreme precipitation events in the midlatitudes (Catto et al. 2012; Catto and Pfahl 2013).

While previous studies have documented the cause of extreme events in the northeastern United States, relatively little work has been done to evaluate the climatology of the synoptic structures of these events and how such structures have changed over time in connection with the increase of extreme precipitation. Here we examine these structures in detail, describing the evolution of meteorological fields through the development and aftermath of extreme precipitation events and contrasting, for example, the synoptic structures of weaker and stronger precipitation events to determine what makes an event more extreme. Past studies have suggested there is a weakening of atmospheric circulation during the summer months, prolonging the duration of blocking systems (Coumou et al. 2015). As a result, quasi-stationary patterns could be becoming common and therefore cause an increase in the frequency of extreme precipitation events, which has already been documented in the Balkan Peninsula (Stadtherr et al. 2016).

The datasets and methodology used for this study are provided in section 2. Section 3 focuses on the results; the section is subdivided to present a brief climatology of precipitation and extreme precipitation events in the northeastern United States, a composite analysis of extreme precipitation events, an analysis of the impact of tropical cyclones and closed low pressure systems on extreme precipitation events, and an indication of how the character of extreme events has changed over time. A summary and discussion is provided in section 4 .

\section{Data and methods}

The primary tools for the analysis include observational and reanalysis products. Observations of precipitation are from the gridded Climate Prediction Center (CPC) Unified Gauge-Based Analysis of Global Daily Precipitation at a resolution of $0.25^{\circ} \times 0.25^{\circ}$ (Xie et al. 2007; Chen and Xie 2008). The Modern-Era Retrospective Analysis for Research and Applications, version 2 (MERRA-2), was used to represent the largescale circulation and meteorological quantities that are not easily observed (Bosilovich et al. 2015; R. Gelaro et al. 2016, manuscript submitted to J. Climate). Hourly data from MERRA-2 are available at a spatial resolution of $0.625^{\circ}$ longitude $\times 0.5^{\circ}$ latitude, and daily averages ending at 1200 UTC were computed to match the temporal resolution of the precipitation observations. MERRA-2 features additional observing systems and improvements to the hydrological cycle not present in the original MERRA (Rienecker et al. 2011), including the forcing of the land surface with observation-based precipitation fields and the implementation of a moisture constraint, preventing an imbalance in global precipitation and surface evaporation (Reichle and Liu 2014; Takacs et al. 2016). MERRA-2 also features numerous developments in the underlying model (Molod et al. 2015), such as in the surface layer and boundary layer parameterizations and in the cumulus convection scheme. The data assimilation has been updated to the latest Gridpoint Statistical Interpolation analysis scheme version and includes global dry mass constraints that help minimize spurious temporal variability effects (Takacs et al. 2016). Also, new observations not available to the original MERRA have been added, such as GPS radio occultation and the Infrared Atmospheric Sounding Interferometer (McCarty et al. 2016).

We focus in this paper on the northeastern United States region outlined in Fig. 1, a region that includes land areas between $40^{\circ}$ and $45^{\circ} \mathrm{N}$ and $70^{\circ}$ and $76^{\circ} \mathrm{W}$. This region was selected based on an analysis of the seasonal climatological means and interannual variability over the past 30 years in an effort to reduce spatial variability in precipitation within the Northeast region as defined by the National Climate Assessment (Horton et al. 2014). Figures that were used to further define the Northeast region can be seen in the supplemental material.

Using the CPC gauge observations, daily precipitation values for the area as a whole are computed, and 

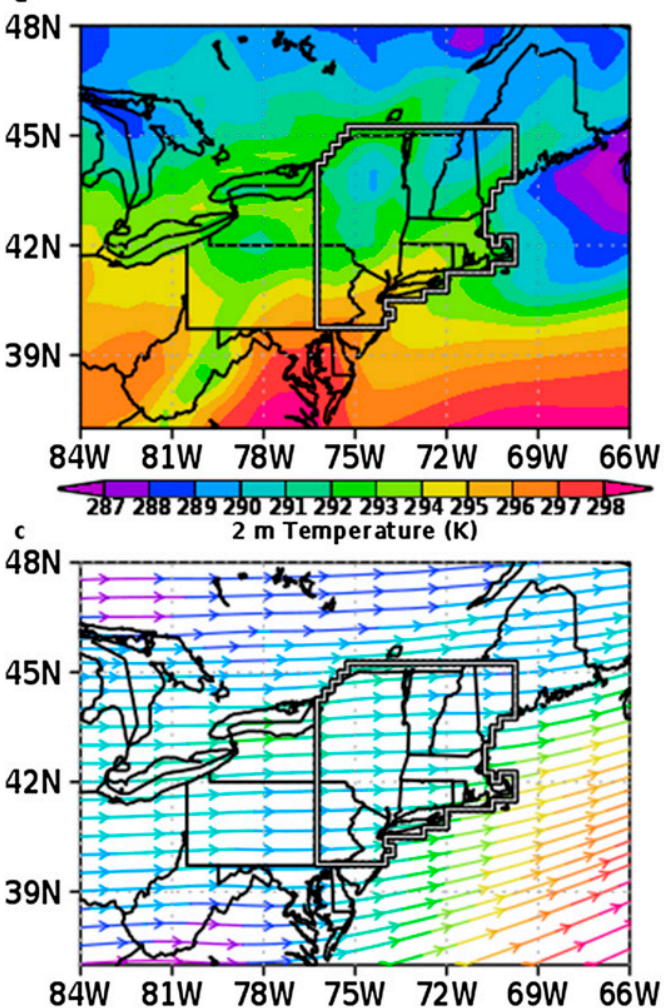

143154165176187198209220231242253264 Vert. Int. Q Flux $\left(\mathrm{kg} \mathrm{m}^{-2} \mathrm{~s}^{-1}\right)$ b

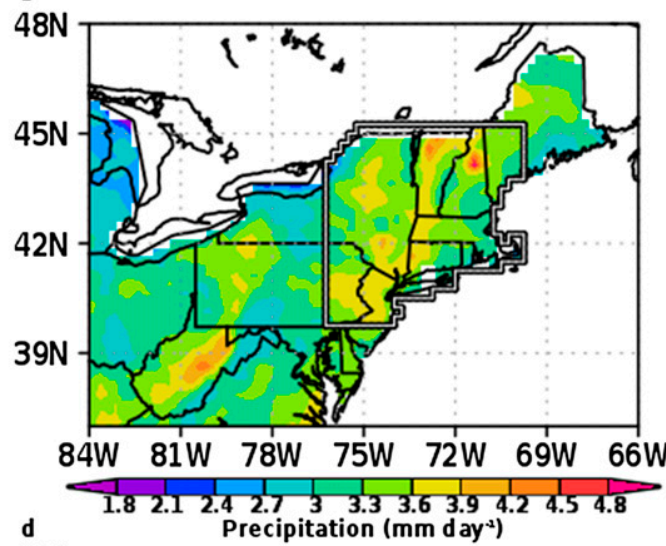

$48 \mathrm{~N}$
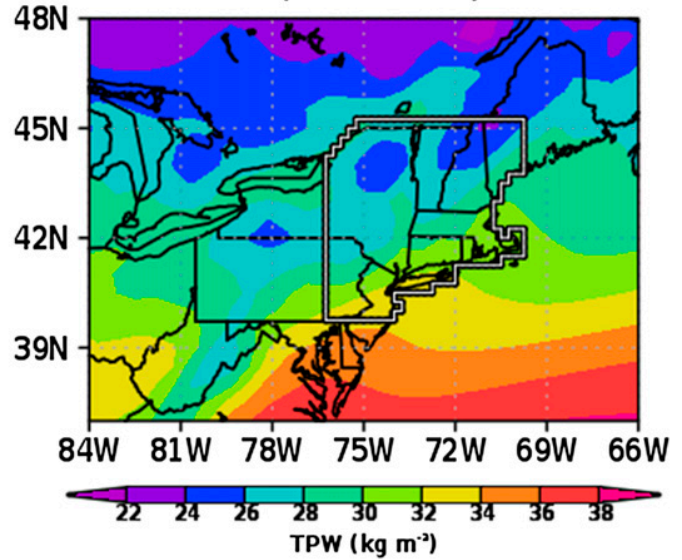

FIG. 1. Mean JJA (a) 2-m temperature, (b) observed precipitation, (c) vertically integrated water vapor flux, and (d) TPW over the period 1980-2014. The Northeast region as defined in this study is outlined in black.

percentiles are then calculated from these spatial averages among the days with at least $1 \mathrm{~mm}$ of precipitation, following Rivera et al. (2014), Hirata and Grimm (2016), and Westby and Black (2015). The 1-mm threshold is used to ensure that only days with a precipitation event are included in the percentile calculation. Keep in mind that the nature of our results will depend in part on the area used here for the averaging; larger regions may favor widespread heavy precipitation as opposed to local or regional extreme precipitation. Given the area we use, many of the events we examine are widespread and on the synoptic scale, impacting most of the region.

Percentiles were defined separately for each day of the year using a window around each date of \pm 1 week and then considering together the daily precipitation values during the 2-week period in each year from 1981 through 2010. This window around each date allows for more robust statistics while maintaining any differences associated with seasonality. Warm and cold season extreme precipitation events differ in frequency and intensity, and this methodology allows for seasonal variations in precipitation to be taken into account (Frei et al. 2015). In this study, we focus on June-August (JJA).

Frei et al. (2015) classified extreme precipitation events using 90th, 95th, and 99th percentiles, and the Climate Data Operators (CDO) and the Expert Team on Climate Change Detection and Indices (ETCCDI; Alexander et al. 2006) classified them using 75th, 95th, and 99th percentiles. Here we focus on the 75th and 95th percentiles, with events falling into the category if they are within a range of \pm 5 percentile units of the noted values. That is, the 75th percentile grouping, or composite, does not include the more extreme events found in the 95th percentile composite and can thus be considered a composite of relatively weaker events. By definition, there are a similar number of events in both groupings $(\sim 200$; see Table $\mathrm{S} 1$ in the supplemental material). This number is representative of roughly $10 \%$ of the number of days with at least $1 \mathrm{~mm}$ of precipitation as opposed to the total number of days within the time period due to the threshold used in the percentile calculation. Note that such a compositing approach has been used to study events (e.g., atmospheric rivers) in 
other regions (Grotjahn and Faure 2008; Warner et al. 2012; Gao et al. 2014).

While MERRA-2 shows significant improvements over MERRA in the representation of extreme precipitation events, there are still uncertainties associated with modeled precipitation (Bosilovich et al. 2015). MERRA-2 and the CPC gauge data do not contain exactly the same number of days above $1 \mathrm{~mm}$ to be included in the percentile calculations and therefore do not result in the same number of events that exceed a given percentile. More importantly, there are a number of dates that are considered extreme in the observations and not in MERRA-2, and vice versa. As a result, only the observations are used here to determine whether an event falls in the 75th or 95th percentile categories. Using observations to determine extreme precipitation events and reanalysis data for the large-scale circulation is a common methodology used in past studies (e.g., Gao et al. 2014).

\section{Results}

\section{a. Climatology of the northeastern United States}

Having both mountains and a coastline, the climate in the Northeast is greatly influenced by geography, and the region is susceptible to different varieties of weather including hurricanes, extratropical cyclones, mesoscale systems, heat waves, and drought during the summer months. Mean climate features during JJA over the period 1980-2014 in MERRA-2 are shown in Fig. 1. Temperature at $2 \mathrm{~m}$ tends to decrease with increasing latitude (Fig. 1a). Cooler temperatures over the ocean inhibit daytime warming along the coast and higher elevations associated with the Appalachian Mountains result in cooler temperatures, most notably over eastern New York. The mountains also play a role in mean daily precipitation, with precipitation enhanced over the higher elevation (Fig. 1b).

The availability of moisture is a key component of precipitation events, and information about this availability, for example, in the form of vertically integrated water vapor flux, is a unique feature of reanalyses such as MERRA-2. Tropospheric winds are generally from the west, with maximum velocities centered around $45^{\circ} \mathrm{N}$ (Figs. S1, S2 in the supplemental material), resulting in a mean eastward transport of water vapor (Fig. 1c). Vertically integrated moisture fluxes positioned over land are also higher near the coast, most notably over Rhode Island and Cape Cod, Massachusetts, with the Atlantic Ocean serving as a source of moisture. Moisture from the Atlantic Ocean can also be seen in the total precipitable water vapor (TPW) along the coast (Fig. 1d).
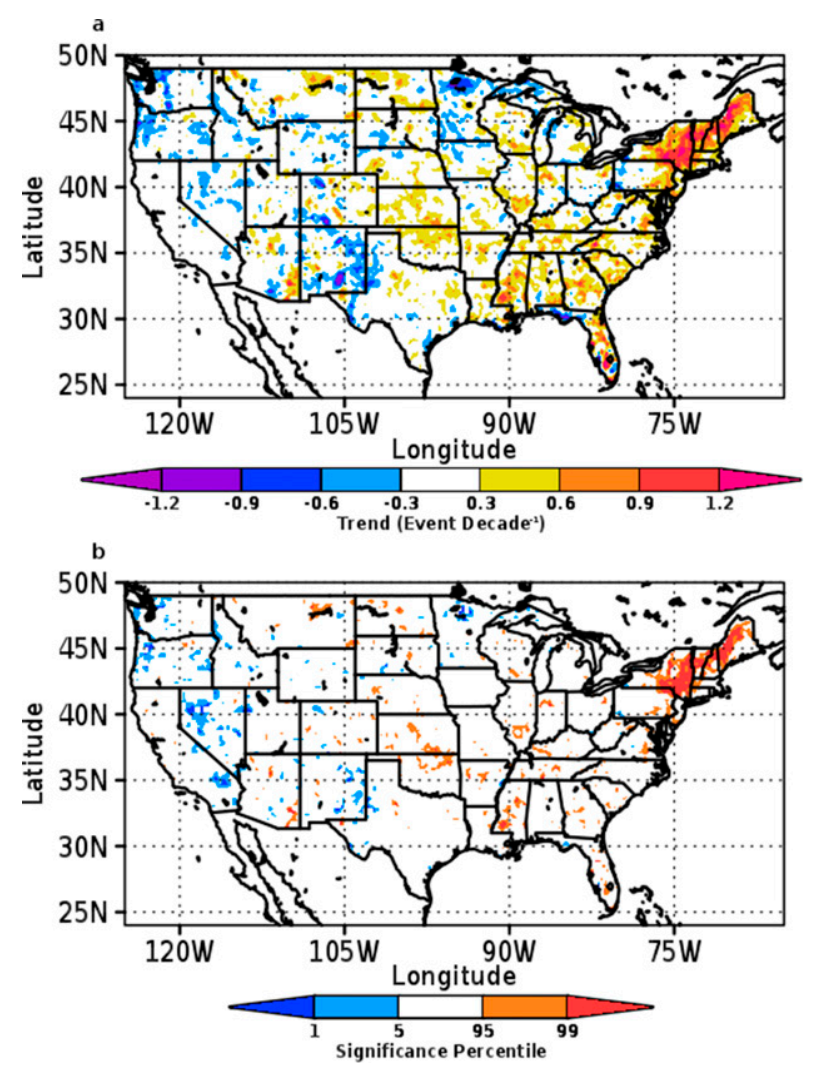

FIG. 2. (a) Trend in the number of JJA precipitation events at the 95th percentile. (b) Significance of the trend in (a) as calculated using a Monte Carlo simulation.

While summertime extreme precipitation frequency has changed over time in numerous locations within the United States, the Northeast shows the largest increase in the frequency of extreme events at the 95th percentile, according to the CPC gauge observations (Fig. 2). The 95th percentile used for Fig. 2 was defined for each $0.25^{\circ} \times 0.25^{\circ}$ grid box in the observations. Most of the region has seen an increase greater than one such event per decade (Fig. 2a). The significance of the trend was evaluated using a Monte Carlo simulation; results show that in many parts of the Northeast, the observed trend is significantly different from zero at the $99 \%$ confidence level (Fig. 2b).

A time series for area-averaged observed precipitation within the region of interest is presented in Fig. 3a (black curve). Based on a least squares regression and a Student's $t$ test, there is a statistically significant upward trend in mean precipitation over the 36-yr time period. A closer look at the time series indicates that the increase over time is in fact superimposed on an oscillation or a shift that occurs in the late 1990s; this might be related to the Atlantic multidecadal oscillation, which has been shown to be positively correlated to summertime 

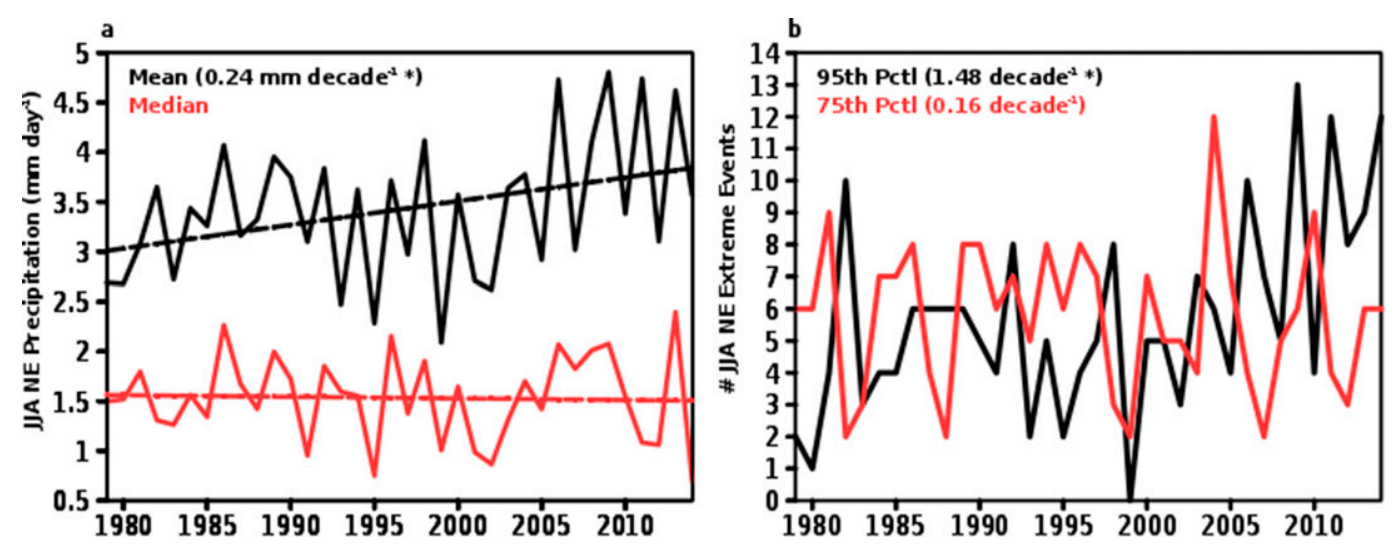

FIG. 3. (a) Area-averaged mean and median observed JJA precipitation in the Northeast during 1979-2014. (b) The number of 75th and 95th percentile JJA precipitation events in the Northeast. Trends calculated with a least squares progression are given in parentheses and asterisks indicate statistical significance at a $95 \%$ confidence interval.

precipitation and extreme precipitation in the northeastern United States (Enfield et al. 2001; Curtis 2008). It has been shown that the positive phase of the Atlantic multidecadal oscillation leads to an area of decreased sea level pressure and a cyclonic circulation off the East Coast (Knight et al. 2006; Curtis 2008). This cyclonic circulation is believed to increase the flow of low-level moisture into the region that is forced to rise because of orographic lift from the Appalachian Mountains, therefore leading to more frequent intense precipitation events.

While mean precipitation in the Northeast has increased over time, the median has not (Fig. 3a, red curve). This implies that while extreme precipitation events are increasing, nonextreme events are not. This point is further emphasized in Fig. 3b, which shows the time series of 75th and 95th percentile precipitation events (in terms of number of events). While there is considerable interannual variability in the number of 75th percentile precipitation events, their frequency does not change over time. For the 95th percentile events, however, there is a steady increase in number after the late 1990s, with a linear trend over the entire period that is statistically significant at the $95 \%$ confidence interval.

\section{b. Composited fields during extreme precipitation events}

Using extreme precipitation events over the Northeast (as determined from the daily gauge observations) as the basis for compositing, we compute composites of various meteorological fields from MERRA-2. Total precipitation composited using the 75th and 95th percentile Northeast precipitation events is shown in Fig. 4. For both intensities, a wide area, spanning the entire East Coast, sees significant precipitation (on average)

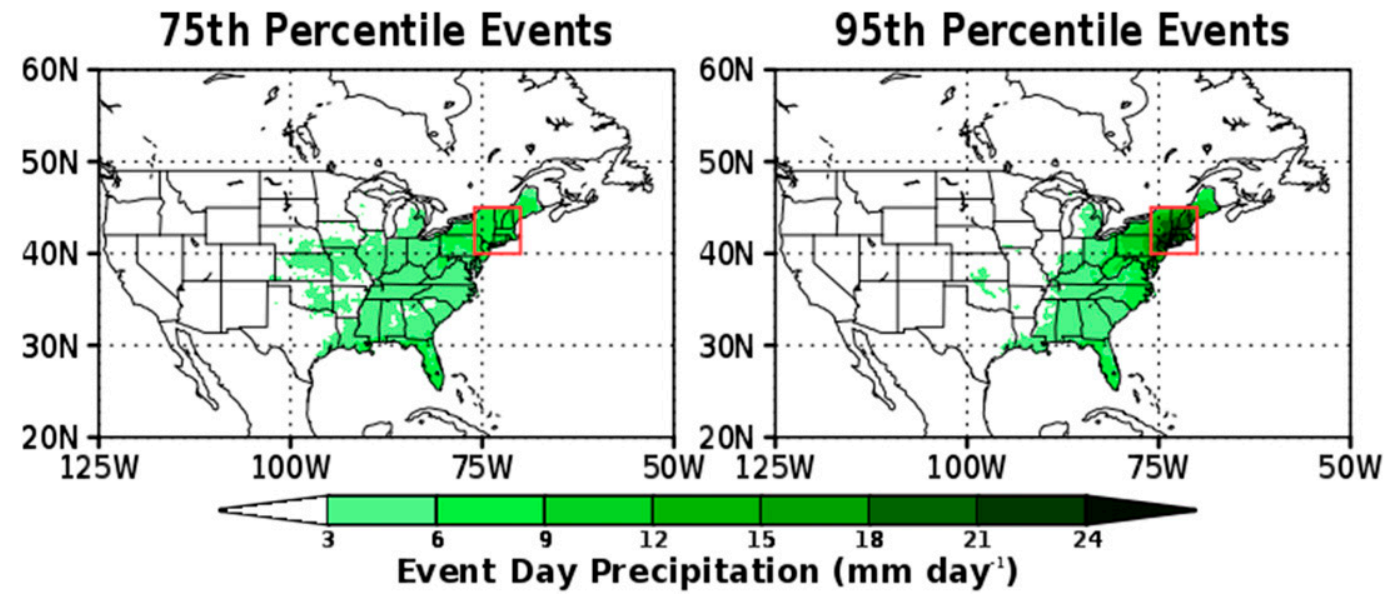

FIG. 4. Observed precipitation composited during (left) 75th and (right) 95th percentile events. 
during these events. Our methodology clearly pulls out large-scale events that cover an area much larger than the defined Northeast region. The daily average precipitation may in fact capture precipitation from a system that traveled through and impacted a different region earlier in the day. The composite based on the 95th percentile indicates that the heaviest observed precipitation fell in the southern portion of the Northeast region, along the coastline.

A key component of extreme precipitation events is the availability of moisture in the region. Figure 5 shows the anomalous flow of moisture, more specifically, anomalies in the vertically integrated water vapor flux, into the Northeast before, during, and after these events, as represented by the two sets of composites. Values below $40 \mathrm{~kg} \mathrm{~m}^{-1} \mathrm{~s}^{-1}$ have been masked out to draw attention to larger anomalies. From 2 days out there is little difference between climatology and 75 th percentile precipitation events, with the only anomaly being a hint of a trough beginning to take shape in the northern Great Plains and Midwest (Fig. 5a). This anomaly is amplified in magnitude and area in the 95th percentile composite, with the center shifted to the south (Fig. 5b). The day prior to an extreme precipitation event, the vertically integrated moisture flux anomalies become stronger, forming a cyclonic circulation; again, the cyclonic circulation is stronger and slightly farther south in the 95th percentile anomaly composite (cf. Figs. 5c,d). Moisture flux anomalies are strongest in the southern portion of the circulation. Anomalies are likely stronger to the south from the convergence of moisture coming from the west and moisture from the Gulf of Mexico. The increased flow of moisture from the Atlantic Ocean apparent in the 95th percentile composite for the day prior to the event is somewhat deceptive. In that region, moisture fluxes in the composite are oriented from the southwest but are smaller than what is seen in the climatology, and this is manifested in the anomaly field as a change in direction that makes it look as if moisture is brought into the region from the Atlantic Ocean (Fig. S3 in the supplemental material).

On the day of the extreme precipitation event, the circulation pattern represented by the vertically integrated moisture flux anomalies takes on an elongated shape, with a tilt from the southwest to northeast (Figs. 5e,f). The largest anomalies are now on the east side of the circulation, with moisture being pulled in from the Atlantic Ocean in the warm conveyor belt of enhanced southerly flow. Anomalies extend farther south in the 95th percentile events, with decreased moisture transport into Texas and Louisiana (Fig. S3 in the supplemental material), and with an increased westerly and southwesterly flow of moisture in the southeastern portion of the country. The Gulf of Mexico serves as a moisture source for the 95 th percentile composite, but not so much for the 75th percentile composite. An additional difference between the 75th and 95th percentile events is seen in the easterly anomalies over the Atlantic Ocean, which are absent during 75 th percentile events.

The day after the extreme precipitation event, the circulation pattern leaves the region with a shift toward the northeast. For the 75th percentile composite, as the pattern nears the Atlantic Ocean, the region of maximum moisture flux anomalies is broader than it was on the day of the event.

As moisture is conveyed from the Gulf of Mexico and Atlantic Ocean, positive anomalies of TPW develop over the Northeast, as seen in Fig. 6. TPW anomalies are weak 2 days prior to an extreme precipitation event but become more significant the day before the event. Maximum TPW anomalies are centered east of the Great Lakes in both the 75th and 95th percentile cases; however, the anomalies are stronger for the latter composite. The shape of the 75th percentile positive TPW anomaly is indicative of an extratropical cyclone, whereas the 95th percentile anomaly appears broader. Relatively drier air develops to the west, concurrent with the enhanced northerly flow. TPW anomalies are stronger on the day of the event and become tilted from southwest to northeast, similar to what was seen with the vertically integrated moisture flux anomalies. As the system exits the region the following day, the magnitude of the anomaly does not decrease as the anomaly propagates eastward and moisture becomes available from the Atlantic Ocean.

The anomalies of the vertically integrated water vapor flux provide some indication of the overall flow in the troposphere during extreme precipitation events. However, wind anomalies in the upper troposphere, in this case at $250 \mathrm{hPa}$, can also provide information regarding the dynamics surrounding extreme precipitation events. This is illustrated in Fig. 7. Anomalies below $3 \mathrm{~m} \mathrm{~s}^{-1}$ have been masked out to highlight the more significant anomalies. In the climatology (not shown), the strongest winds in the jet stream are located between $40^{\circ}$ and $50^{\circ} \mathrm{N}$ with a general westerly flow. Two days prior to an extreme precipitation event, a stronger meridional component of the 250 -hPa winds is seen along the U.S.-Canada border around Montana and the Great Lakes. On the day before the event, these wind anomalies become stronger and develop a cyclonic pattern centered around Minnesota. Wind speed divergence is seen in the Midwest region, with directional divergence to the northeast along the border of Ontario and Quebec. This divergence in the upper troposphere can signal convergence at the surface and upward vertical motion in the 

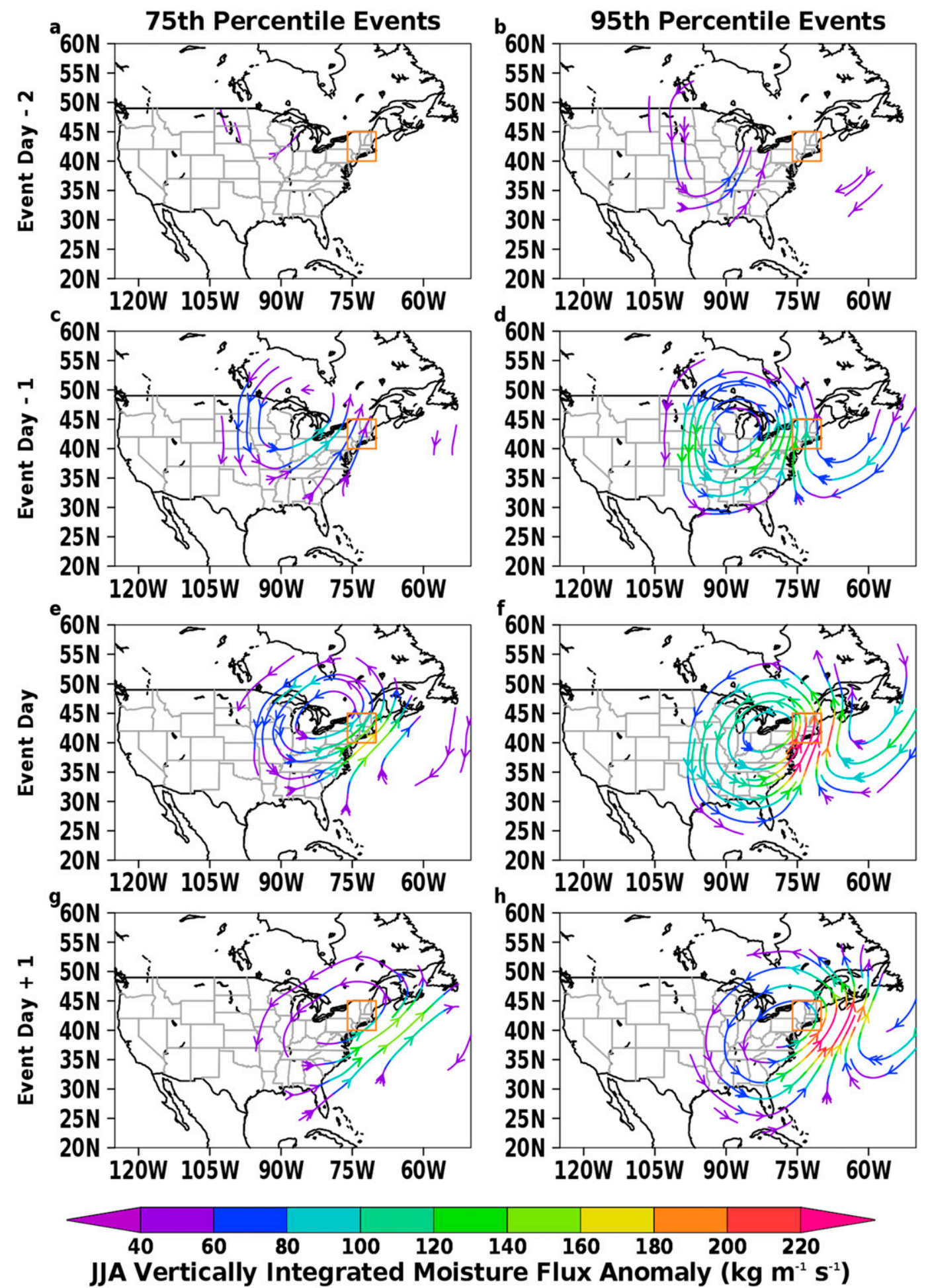

FIG. 5. Vertically integrated water vapor flux anomalies composited from 2 days prior to 1 day after an observed (left) 75 th and (right) 95 th percentile precipitation event. Anomalies below $40 \mathrm{~kg} \mathrm{~m}^{-1} \mathrm{~s}^{-1}$ are masked out. 

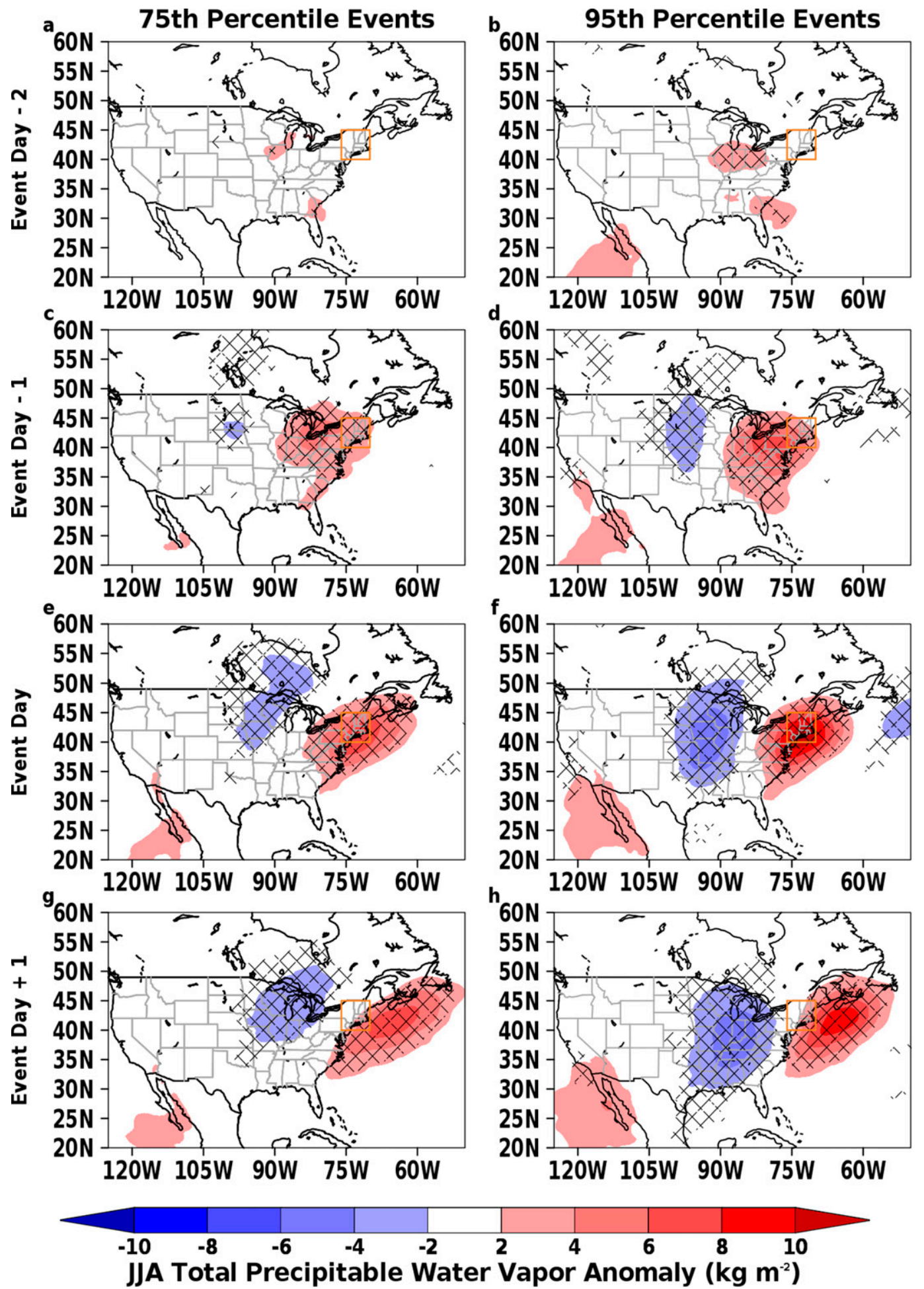

FIG. 6. TPW anomalies composited from 2 days prior to 1 day after an observed (left) 75 th and (right) 95th percentile precipitation event. Hatching denotes regions with a statistical significance of $95 \%$. 

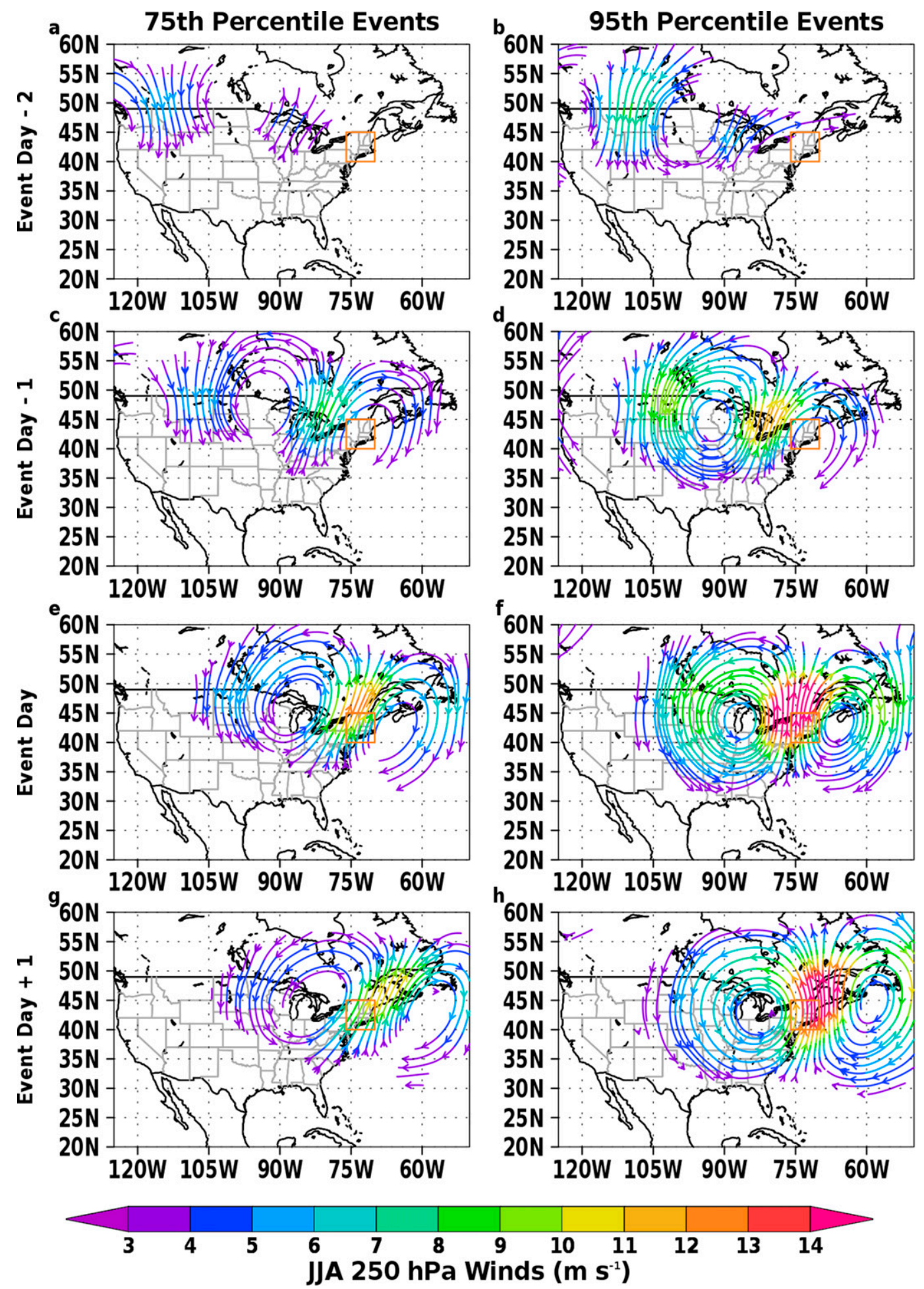

FIG. 7. The 250-hPa wind anomalies composited from 2 days prior to 1 day after an observed (left) 75 th and (right) 95th percentile precipitation event. Anomalies below $3 \mathrm{~m} \mathrm{~s}^{-1}$ are masked out. 
column, a suitable component to an extreme precipitation event.

The strongest $250-\mathrm{hPa}$ wind anomalies are present on the day of the extreme precipitation event, with maxima in the northwestern quadrant of the selected Northeast region. The entire region is located in the right entrance region of enhanced upper-level winds, where upward vertical motion occurs. These maxima in the anomaly fields are oriented toward the northeast in the 75th percentile events but have a more northward orientation in the 95th percentile events.

Two days prior to an extreme precipitation event, a trough develops upstream of the region of interest in both the 75th and 95th percentile composites of 500-hPa heights (Figs. 8a,b). The negative height anomaly is generally stronger and located slightly to the south in the 95th percentile case. In both cases the trough is embedded in a wave train oriented east to west. The trough tracks to the southeast, with movement slowing between the day of and the day after an extreme precipitation event.

Notice in Fig. 8 that the low-high dipoles around the event are stronger in magnitude for the 95th percentile composite. The negative anomaly in 500 -hPa height is accompanied by a similar pattern in sea level pressure anomalies, though the low pressure system is not vertically stacked (Fig. 9). The positive anomaly to the east of the negative anomaly at $500 \mathrm{hPa}$ develops coherently with the low in sea level pressure in the 95th percentile composite, but not in the 75th. Negative sea level pressure anomalies become elongated the day of the event and the day after the event. The shape of the negative sea level pressure anomaly, particularly in the 95th percentile case the day after the event, resembles a low pressure system and trailing cold front.

A reduction in cutoff lows has been shown to be responsible for a reduction in precipitation in southern Australia, and a change in blocking patterns could cause the opposite response in the United States (Risbey et al. 2013). Following the methodology of Pook et al. (2006), an event was determined to be caused by a cutoff low if MERRA-2 indicated a closed area of sea level pressure below $1008 \mathrm{hPa}$ with a trough at $500 \mathrm{hPa}$, or a closed contour in 500-hPa height, alongside a negative anomaly in $1000-500 \mathrm{hPa}$ thickness of at least $20 \mathrm{~m}$ compared to climatology within the synoptic region. The number of 95th percentile extreme precipitation events related to cutoff lows as a function of year is shown in Fig. 10a, along with the time series of the total number of extreme events. While there is a statistically significant increasing trend in events caused by a cutoff low, this trend is not large enough to account for the total observed increase in extreme precipitation events in the Northeast. On the other hand, despite year-to-year variability, there is no change over time in the number of 75th percentile events caused by cutoff lows.

\section{c. Tropical extreme precipitation events}

Previous studies of extreme precipitation events in the Northeast indicate that the percentage of summertime extreme events caused by tropical cyclones can exceed 25\% (Kunkel et al. 2012; Agel et al. 2015). This number is very dependent on the methodology used to define an extreme event and a tropical cyclone. Following Kunkel et al. (2012), we define an extreme Northeast event to be caused by a tropical cyclone if a storm listed in the National Hurricane Center "best track" hurricane database (HURDAT) was within $5^{\circ}$ of the Northeast region. Given our definition of an extreme event as falling within \pm 5 percentile units of the 95th percentile, we find the percentage of extreme precipitation events in JJA caused by a tropical cyclone to be a relatively low $10.6 \%$, though we are focusing on a smaller region than in the previous studies and are using percentile-based approach to define events. In contrast, Kunkel et al. (2012) use a threshold (which does not vary with time of year) to define events based on a return period of 5 years, and they areal average the number of events caused by tropical cyclones for a larger spatial area, one that spans from Maine through West Virginia.

Most of the extreme events we have linked to tropical cyclones are in the more recent time period; only two occur in the 1980s (Fig. 11a), and both of these events are related to Tropical Storm Chris, which traveled through the region in 1988 as a tropical depression. There is no significant linear trend in the time series of events caused by tropical cyclones during 1985-2014, as there are never more than two events in a given year. The total number of extreme precipitation events per year, on the other hand, does have a statistically significant trend (Fig. 3b).

The average intensity of an event is somewhat determined by the methodology used to define an event, and this intensity hovers around $20 \mathrm{~mm} \mathrm{day}^{-1}$ for all events (Fig. 11b). Aside from 2011 and 2013, which saw nearly doubled intensities because of Hurricane Irene and Tropical Storm Andrea, the average intensity of the tropical cyclone-related events is roughly the same. The total seasonal precipitation from extreme events (Fig. 11c) is thus more closely related to the number of events than their intensity. There are a number of years without any hurricanes but with a high total accumulation from extreme events (e.g., 1982, 1998, and 2006). While the largest accumulation from extreme events occurred in 2011, coinciding with the maximum average intensity due to tropical cyclones, overall there is no 

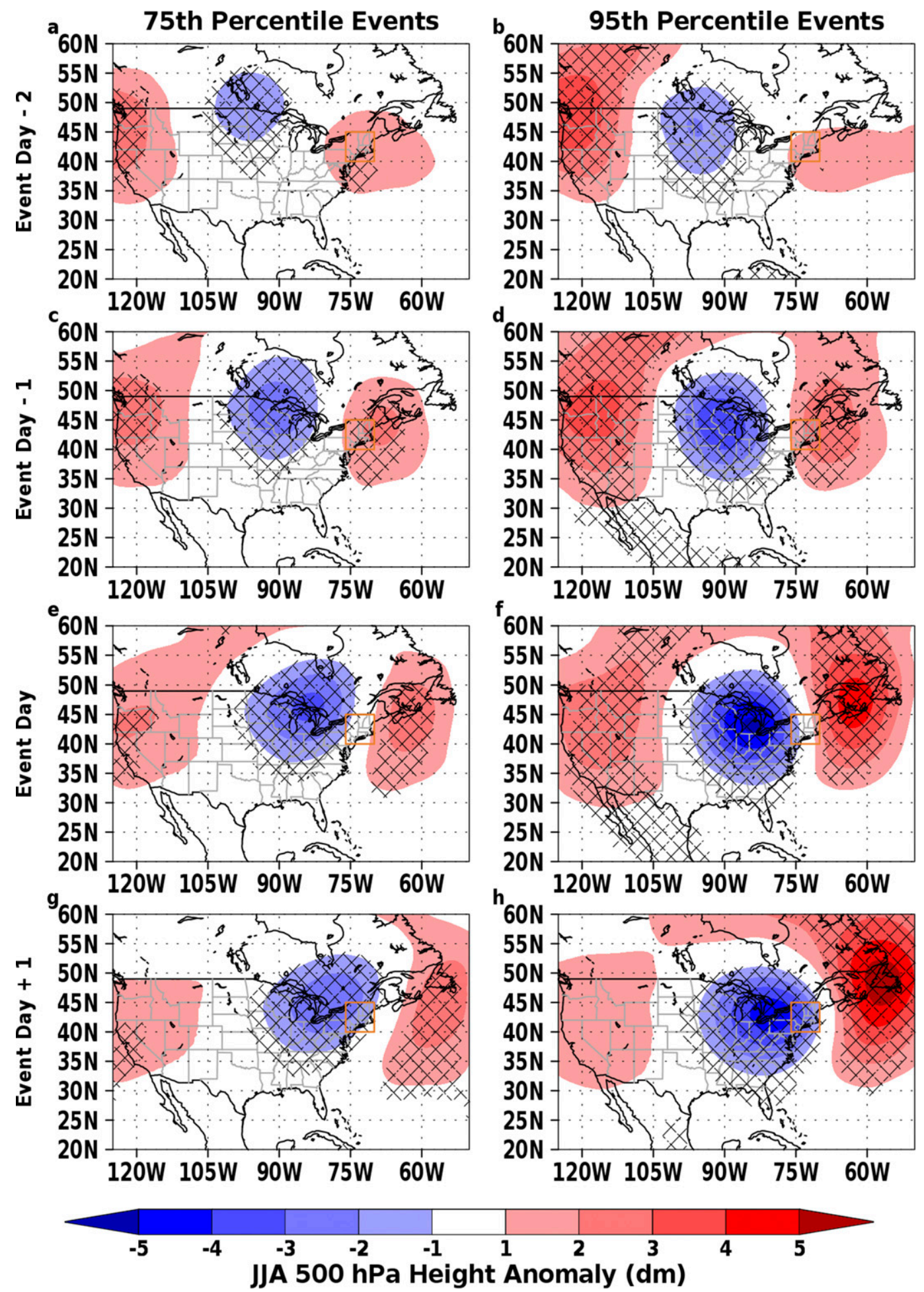

FIG. 8. The 500-hPa height anomalies composited from 2 days prior to 1 day after an observed (left) 75 th and (right) 95th percentile precipitation event. Hatching denotes regions with a statistical significance of $95 \%$. 

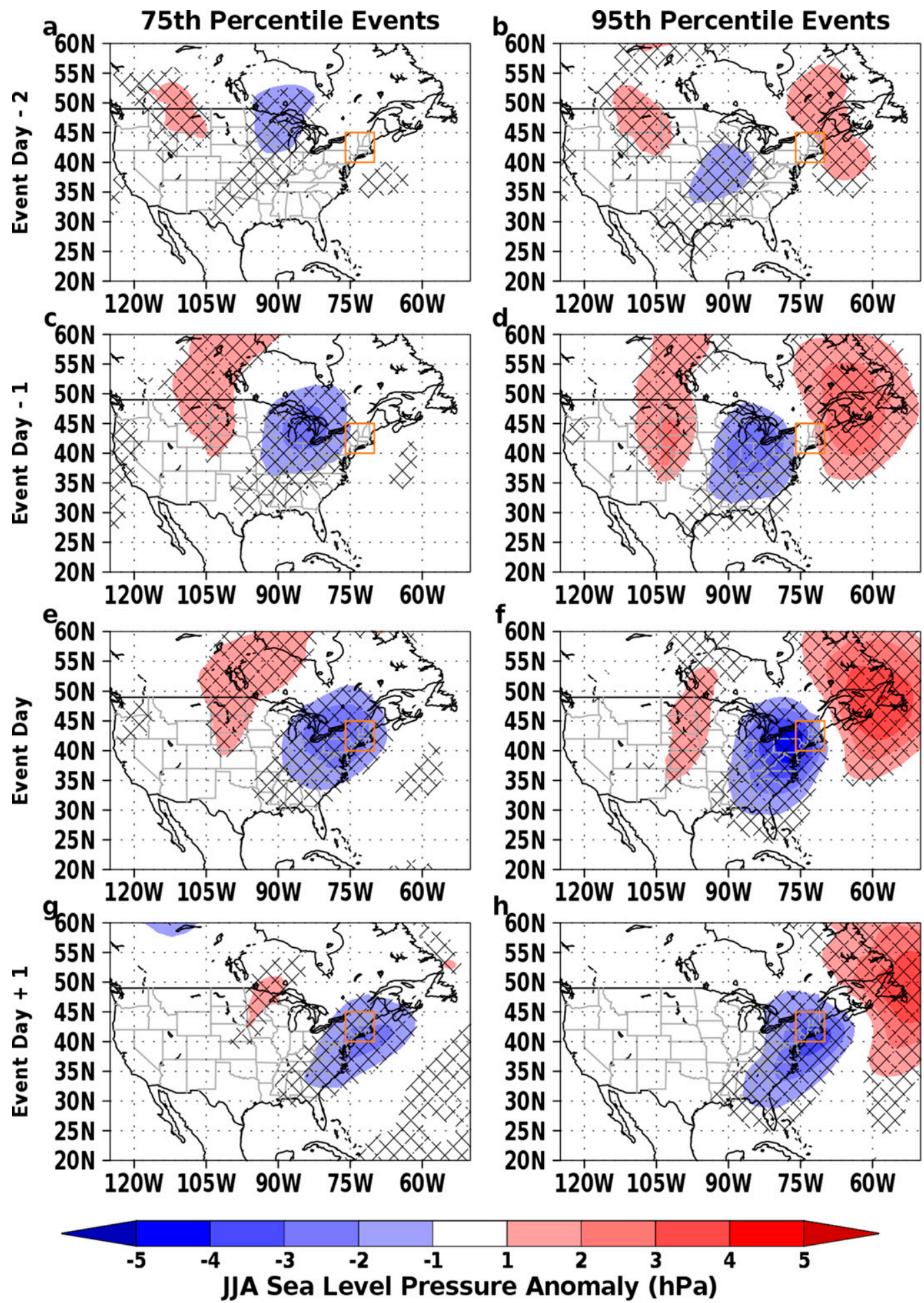

FIG. 9. Sea level pressure anomalies composited from 2 days prior to 1 day after an observed (left) 75 th and (right) 95th percentile precipitation event. Hatching denotes regions with a statistical significance of $95 \%$. 

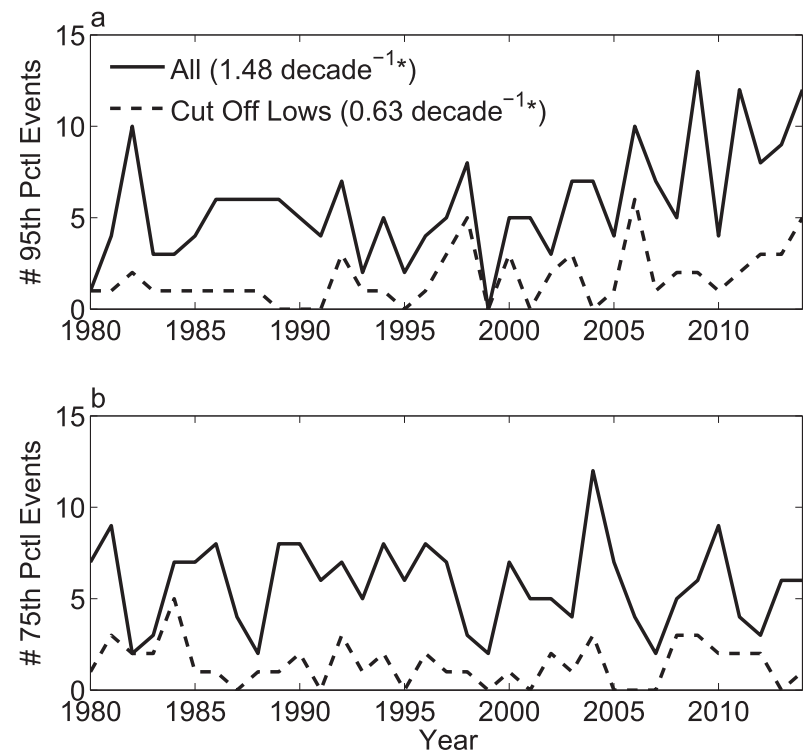

FIG. 10. Time series of the number of total events and those caused by a cutoff low for the (a) 95th and (b) 75th percentile.

statistically significant indication that tropical cyclones are responsible for the increase in extreme precipitation events in the Northeast.

When events caused by a tropical cyclone are removed from the 95th percentile events, the composited sea level pressure and 500-hPa heights on the day of the extreme precipitation events (not shown) do not change much from those seen in Figs. $8 \mathrm{f}$ and $9 \mathrm{f}$. This is likely due to the fact that only a small fraction of events were removed-only 21 out of $\sim 200$ precipitation events at the 95th percentile between 1980 and 2014 matched a tropical cyclone in HURDAT. Figure 12 shows the sea level pressures composited on these 21 cyclone-related events. (Note that there were not enough events in the 75 th percentile category to allow a corresponding analysis.) Leading up to the day of an extreme precipitation event, an area of suppressed sea level pressure can be seen coming up the coast rather than moving in from the northwest, as in Fig. 9 (for all 95th percentile events). There is a wider trough in sea level pressure for the tropical cyclone-related events, though caution must be taken with a direct comparison because the different composites are based on a different number of events. One commonality between Figs. 9 and 12 is the region of a positive sea level pressure anomaly to the northeast, helping to steer the region of low pressure.

\section{d. Change in composites over time}

To examine factors that may induce changes in extreme precipitation over time, we compare composites from the first half of the MERRA-2 time period (1980-96) to those

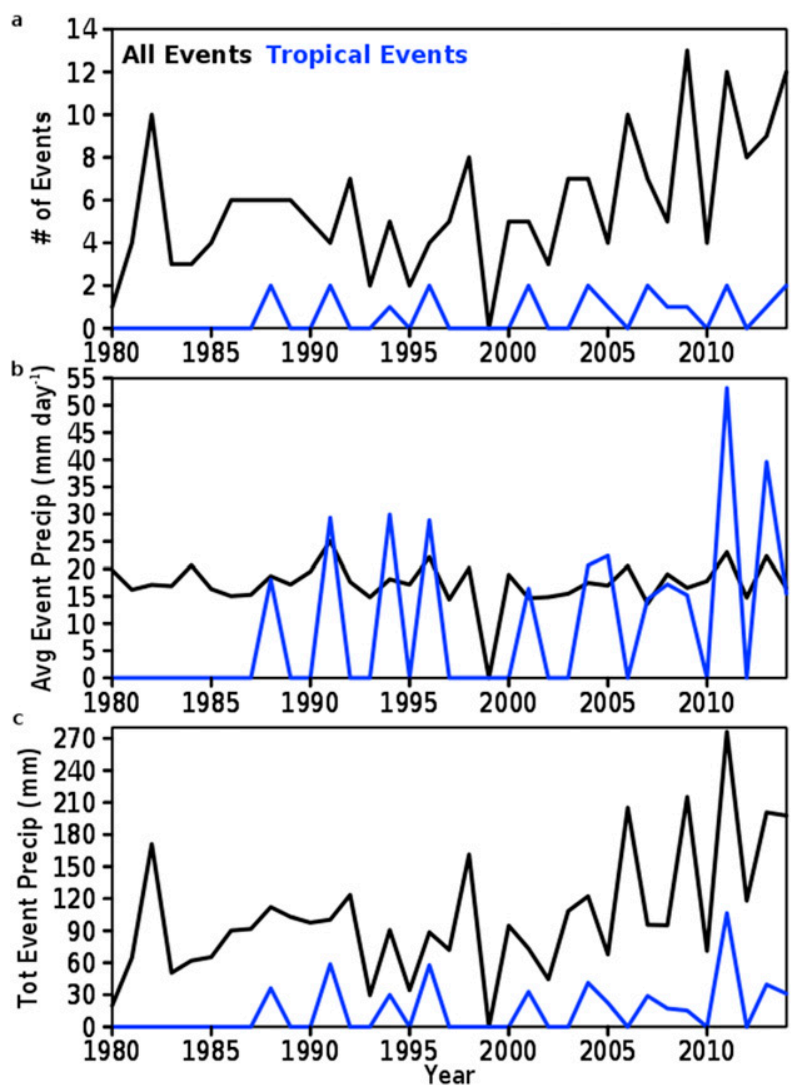

FIG. 11. (a) Time series of number of total and tropical 95th percentile events in the Northeast during JJA. (b) Time series of the average intensity of a 95th percentile event in the Northeast during JJA. (c) Time series of the total amount of precipitation from a 95th percentile event for all events and those caused by a tropical cyclone in the Northeast during JJA.

constructed from the second half (1997-2014) using the same time series of extreme events as the previous composites. Time difference composites (later period minus early period) for sea level pressure, 500-hPa heights, vertically integrated moisture fluxes, precipitation, Eady growth rate, and a vertical cross section of equivalent potential temperature on the day of a 95th percentile precipitation event are shown in Fig. 13. Note that in contrast to the previous figures, which showed anomalies relative to climatology, Fig. 13 shows the difference in the total fields between the two time periods. Most of the United States saw a decrease in sea level pressure, though the only region with a statistically significant decrease extends from Maine through northeastern Florida (Fig. 13a). The shape of this statistically significant region is reminiscent of a cold front with the northern edge over the eastern half of the selected region, but this can also be indicative of cutoff lows or extratropical cyclones. Cold fronts are a significant contributor to summertime extreme precipitation events 


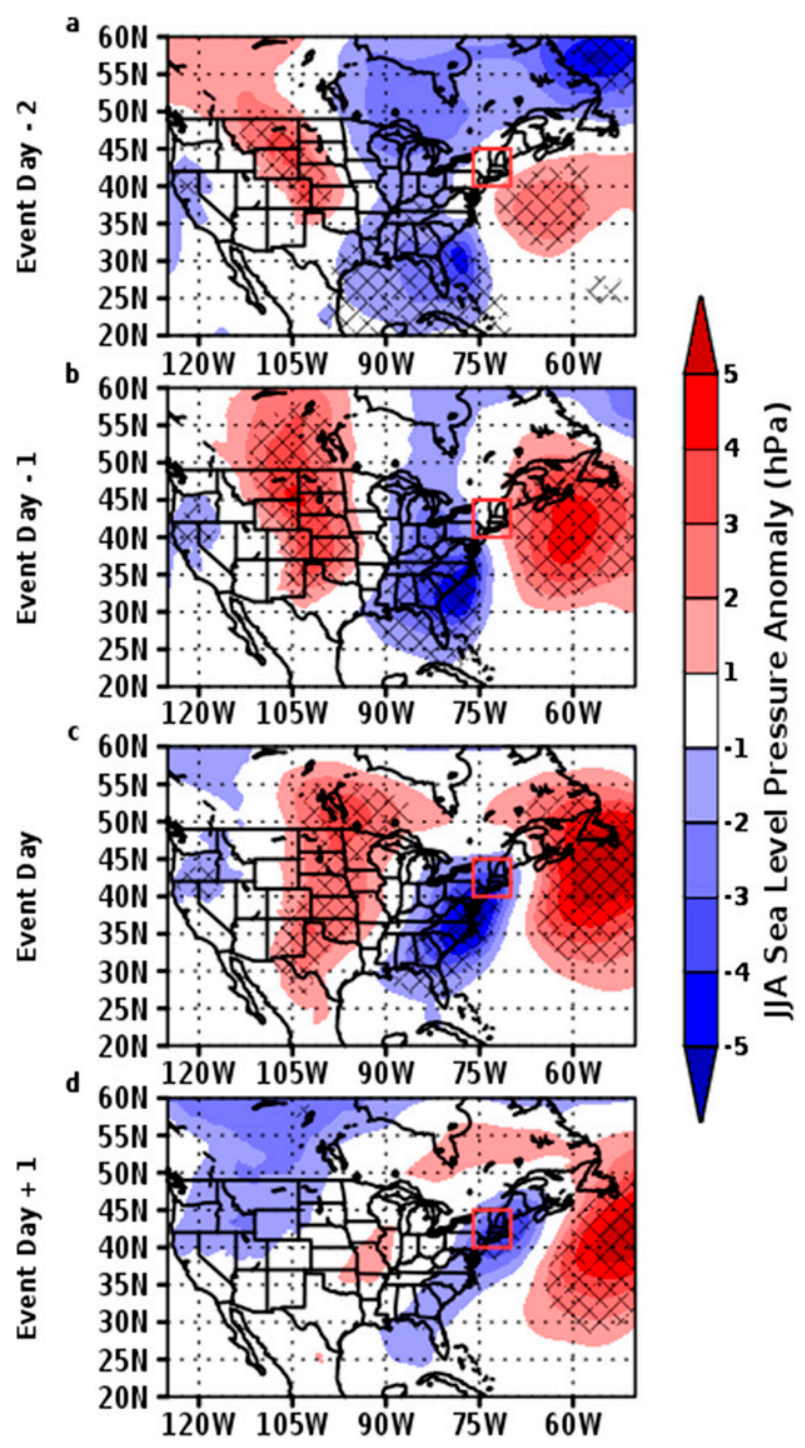

FIG. 12. Sea level pressure anomalies composited from 2 days prior to 1 day after a 95th percentile precipitation event caused by a tropical cyclone. Hatching denotes regions with a statistical significance of $95 \%$.

in the Northeast (Kunkel et al. 2012) and are a potential factor toward the observed increase in extreme precipitation events.

A region of reduced 500-hPa height during 95th percentile events is also present in the later period (Fig. 13b). It was shown earlier that events are not vertically stacked, and this is also indicated by the time difference plots. The region of decreased 500-hPa height lies to the west of the region of decreased sea level pressure, and it also lies to the south, perhaps indicating that more events are taking a track more analogous to a nor'easter rather than an Alberta clipper. An area of statistically significant higher heights is located to the northeast, showing an increase in the pressure gradient over time during extreme precipitation events. Moisture fluxes have also strengthened, particularly over the Gulf Stream (Fig. 13c).

In agreement with the trends seen in Fig. 2, the time difference composite of observed precipitation during 95th percentile events shows an increase through the eastern portion of New York (Fig. 13d). On the other hand, Connecticut, Rhode Island, and Massachusetts have experienced a decrease in this extreme precipitation. Apparently, during the second half of the evaluated time period, the events identified as extreme according to the area-averaged precipitation tended to occur farther to the west, increasing the precipitation in New York and decreasing the precipitation near the coast. This is somewhat in agreement with Fig. 2, which does not show a significant trend in extreme precipitation events in Massachusetts, Connecticut, or Rhode Island.

Baroclinic instability can be a measure of the potential for "storminess" within a region, and one metric for this is the Eady growth rate (Hoskins and Valdes 1990). The change in the maximum Eady growth rate, computed for the layer of 700-300 hPa, between 1980-96 and 1997-2014 during 95th percentile precipitation events is shown in Fig. 13e. The northern edge of the region overlaps a strip of decreased Eady growth rate over time, while there is an increase to the south. This may indicate a southward shift in storm tracks. Extratropical cyclones are typically located farther north in the summer compared to the winter; a southerly shift in Eady growth rate in the summer, however, would indicate that the region could experience more events related to extratropical systems. The statistically significant increase in Eady growth rate just south of the region would place an extratropical cyclone in an ideal location for an onshore flow of moisture into the region along with the dynamics required for precipitation to develop. A comparison to future projections of Eady mean growth rate can be seen in the supplemental material.

To determine if there is a thermodynamic component to the observed changes related to extreme precipitation events, a cross section of the vertical profile of equivalent potential temperature $\theta_{e}$ and specific humidity at $42^{\circ} \mathrm{N}$ was analyzed. A constant latitude was chosen through the center of the region. An increase in $\theta_{e}$, indicated by red shading in Fig. 13f, and specific humidity, indicated by solid black contours, over time can be seen at the surface over the region. These increases slant eastward with increasing height and extend through $300 \mathrm{hPa}$ for $\theta_{e}$; however, humidity is confined to a shallower region within the troposphere. Cooler and drier air lags behind, aside from the increase in $\theta_{e}$ in the upper troposphere. The eastward slant with height in thermodynamic properties furthers the suggestion of an increase in extreme precipitation events 

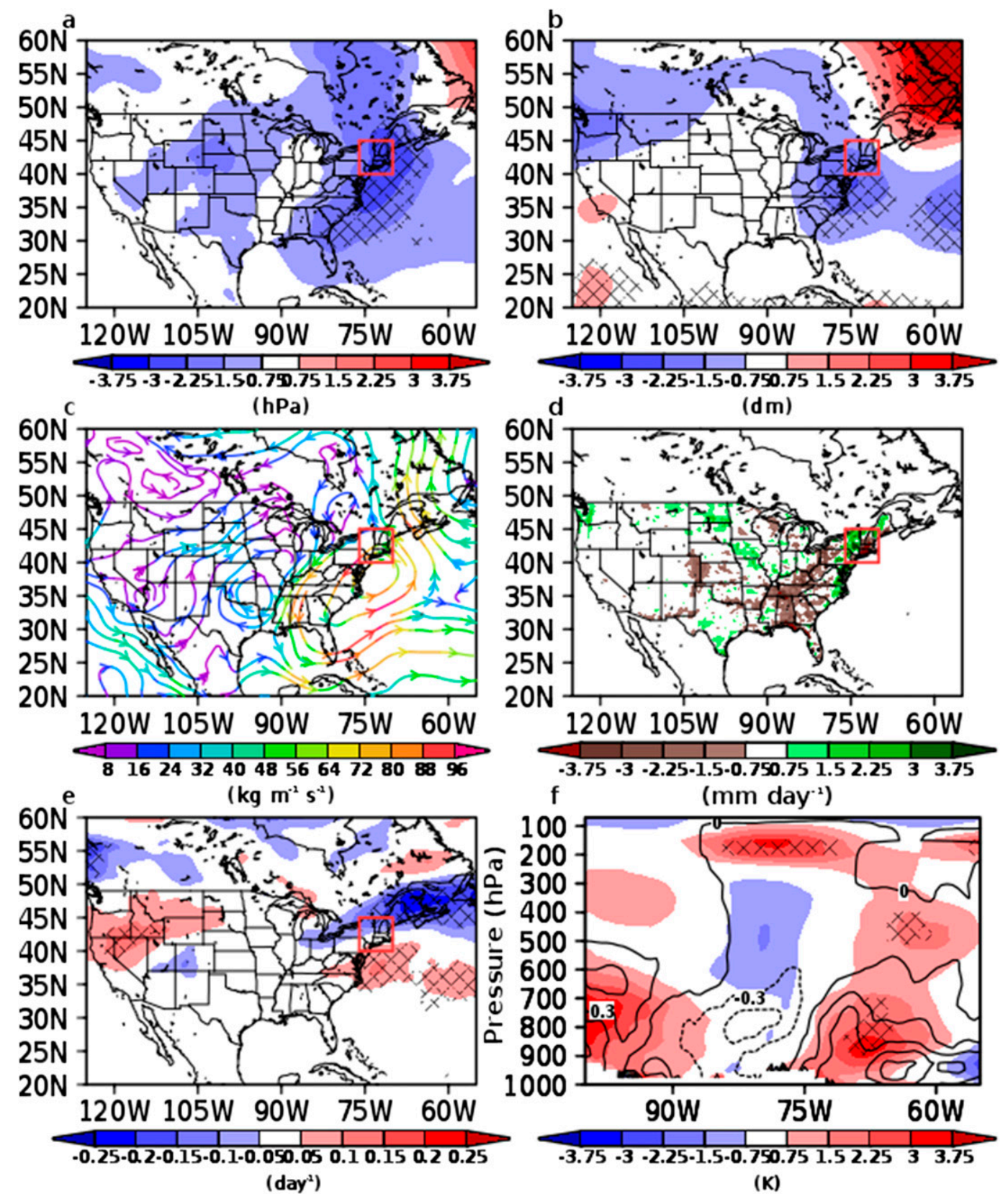

FIG. 13. The difference in (a) sea level pressure, (b) 500-hPa height, (c) vertically integrated moisture flux, (d) observed precipitation, (e) Eady growth rate, and (f) the vertical profile of equivalent potential temperature at $42^{\circ} \mathrm{N}$ composites during 95 th percentile precipitation events calculated by subtracting the mean composite for 1980-96 from the composite for 1997-2014. Hatching denotes regions with a statistical significance of $95 \%$.

associated with frontal activity, though additional work is needed to fully determine if the frequency or intensity of frontal systems has changed over time.

\section{Summary and discussion}

Extreme precipitation events can have large impacts on society, and observations indicate that these events have increased during the months of JuneAugust in the northeastern United States. This increase in extreme precipitation events is statistically significant and is the largest and most widespread change in extreme precipitation in the United States. Based on future climate projections, it is possible this trend will continue, sparking the need for a greater understanding of the details surrounding extreme 
precipitation events in the Northeast (IPCC 2013; Janssen et al. 2014).

In this paper, we examine in detail the character of meteorological fields associated with extreme precipitation events in the Northeast. With observational precipitation records, we construct composites from MERRA-2 of general circulation and synoptic structure leading up to, during, and following extreme precipitation events. Overall, the composites provide evidence of extratropical cyclones that pass through the northeastern United States and produce large amounts of rainfall, with stronger anomalies in dynamical quantities seen for the 95th percentile events. Lower pressures at the surface and divergence aloft allow for upward vertical motion, while the flow around the low pressure area and the high pressure to the east from the associated wave train conveys moisture into the region sufficient enough for heavy rainfall.

Previous studies show the summertime atmospheric circulation has weakened, with an increase greater than $40 \%$ in high-amplitude days in 500-hPa height contours during July-September (Francis and Vavrus 2015; Francis and Skific 2015) and an increase in JJA North Atlantic blocking events (Barnes et al. 2014; Hanna et al. 2015, 2016). As a result, in combination with the trend in Eady growth rate, baroclinic systems that produce extreme events are becoming more stationary. With the Atlantic Ocean providing a vast moisture supply, and with the increasing occurrence of quasi-stationary low pressure systems and frontal systems, extreme precipitation events in the Northeast have become more common. These dynamics have also been demonstrated in studies looking at blocking high pressure systems in relation to Arctic amplification (Coumou et al. 2015). Dynamical changes in addition to the "wet gets wetter" theory and the ability of warmer air to hold more moisture are likely contributors to the increase in extreme precipitation.

Note that convective events are not well represented in our composites. In this paper we identify extreme events by considering precipitation averaged over the Northeast area outlined in Fig. 1, and this area is substantially larger than the spatial scale of individual convective events. In effect, our analysis focuses by construction on large-scale events and the associated character of the large-scale circulation. In addition, by using daily averages of meteorological fields, we further average out characteristics of events that are not caused by large-scale, synoptic features.

There is, of course, still much we can learn about extreme precipitation events in the Northeast using these techniques. There are indications, for example, that extreme events stemming from frontal systems should be separated in our compositing analysis from those associated with extratropical cyclones, given that fronts are a leading cause of summertime extreme precipitation events (Kunkel et al. 2012; Catto and Pfahl 2013), in order to further explore the nature of frontal systems and their connection to the changing extreme precipitation. Also, while our composites show little change when tropical cyclones are removed, this does not necessarily mean that tropical cyclones are not contributing to the increase in extreme precipitation events; it only says that a small percentage of summertime events are caused by tropical cyclones. Using reanalysis data to composite extreme events with a full classification of the underlying systems that generate the extreme rainfall should provide useful information.

Acknowledgments. This work was supported by NASA's Earth Science Research Program. CPC U.S. Unified Precipitation data were provided by the NOAA/ OAR/ESRL PSD, Boulder, Colorado, from their website at http://www.esrl.noaa.gov/psd/. MERRA-2 data were developed by the Global Modeling and Assimilation Office at NASA GSFC and disseminated through the Goddard Earth Science Data and Information Services Center (GES DISC). HURDAT was provided by NOAA/HRD.

\section{REFERENCES}

Agel, L., M. Barlow, J. H. Qian, F. Colby, E. Douglas, and T. Eichler, 2015: Climatology of daily precipitation and extreme precipitation events in the Northeast United States. J. Hydrometeor., 16 , 2537-2557, doi:10.1175/JHM-D-14-0147.1.

Alexander, L. V., and Coauthors, 2006: Global observed changes in daily climate extremes of temperature and precipitation. J. Geophys. Res., 111, D05109, doi:10.1029/2005JD006290.

Barlow, M., 2011: Influence of hurricane-related activity on North American extreme precipitation. Geophys. Res. Lett., 38 , L04705, doi:10.1029/2010GL046258.

Barnes, E. A., E. Dunn-Sigouin, G. Masato, and T. Woollings, 2014: Exploring recent trends in Northern Hemisphere blocking. Geophys. Res. Lett., 41, 638-644, doi:10.1002/2013GL058745.

Bosilovich, M. G., and Coauthors, 2015: MERRA-2: Initial evaluation of the climate. NASA Tech. Memo. NASA/TM-2015104606/Vol. 43, 145 pp. [Available online at https://gmao.gsfc. nasa.gov/pubs/docs/Bosilovich803.pdf.]

Catto, J. L., and S. Pfahl, 2013: The importance of fronts for extreme precipitation. J. Geophys. Res. Atmos., 118, 10791-10801, doi:10.1002/jgrd.50852.

_ C. Jakob, G. Berry, and N. Nicholls, 2012: Relating global precipitation to atmospheric fronts. Geophys. Res. Lett., 39, L10805, doi:10.1029/2012GL051736.

Chen, M., and P. Xie, 2008: CPC Unified Gauge-Based Analysis of Global Daily Precipitation. Western Pacific Geophysics Meeting, Cairns, Australia, Amer. Geophys. Union, Abstract A24A-05.

Coumou, D., J. Lehmann, and J. Beckmann, 2015: The weakening summer circulation in the Northern Hemisphere midlatitudes. Science, 348, 324-327, doi:10.1126/science.1261768. 
Curtis, S., 2008: The Atlantic multidecadal oscillation and extreme daily precipitation over the US and Mexico during the hurricane season. Climate Dyn., 30, 343-351, doi:10.1007/ s00382-007-0295-0.

Enfield, D. B., A. M. Mestas-Nuñez, and P. J. Trimble, 2001: The Atlantic multidecadal oscillation and its relation to rainfall and river flows in the continental U.S. Geophys. Res. Lett., 28 , 2077-2080, doi:10.1029/2000GL012745.

Francis, J. A., and N. Skific, 2015: Evidence linking rapid Arctic warming to mid-latitude weather patterns. Philos. Trans. Roy. Soc. London, A373, 20140170, doi:10.1098/rsta.2014.0170.

_ - and S. J. Vavrus, 2015: Evidence for a wavier jet stream in response to rapid Arctic warming. Environ. Res. Lett., 10, 014005, doi:10.1088/1748-9326/10/1/014005.

Frei, A., K. E. Kunkel, and A. Matonse, 2015: The seasonal nature of extreme hydrological events in the northeastern United States. J. Hydrometeor., 16, 2065-2085, doi:10.1175/JHM-D-14-0237.1.

Gao, X., C. A. Schlosser, P. Xie, E. Monier, and D. Entekhabi, 2014: An analogue approach to identify heavy precipitation events: Evaluation and application to CMIP5 climate models in the United States. J. Climate, 27, 5941-5963, doi:10.1175/ JCLI-D-13-00598.1.

Grotjahn, R., and G. Faure, 2008: Composite predictor maps of extraordinary weather events in the Sacramento, California, region Wea. Forecasting, 23, 313-335, doi:10.1175/2007WAF2006055.1.

Hanna, E., T. E. Cropper, P. D. Jones, A. A. Scaife, and R. Allan, 2015: Recent seasonal asymmetric changes in the NAO (a marked summer decline and increased winter variability) and associated changes in the $\mathrm{AO}$ and Greenland Blocking Index. Int. J. Climatol., 35, 2540-2554, doi:10.1002/joc.4157.

$\_, \ldots$, R. J. Hall, and J. Cappelen, 2016: Greenland Blocking Index 1851-2015: A regional climate change signal. Int. J. Climatol., doi:10.1002/joc.4673, in press.

Hirata, F. E., and A. M. Grimm, 2016: The role of synoptic and intraseasonal anomalies in the life cycle of summer rainfall extremes over South America. Climate Dyn., 46, 3041-3055, doi:10.1007/s00382-015-2751-6.

Horton, R., and Coauthors, 2014: Northeast. Climate Change Impacts in the United States: The Third National Climate Assessment, J. M. Melillo, T. C. Richmond, and G. W. Yohe, Eds., U.S. Global Change Research Program, 371-395, doi:10.7930/J0KW5CXT.

Hoskins, B. J., and P. J. Valdes, 1990: On the existence of storm-tracks. J. Atmos. Sci., 47, 1854-1864, doi:10.1175/ 1520-0469(1990)047<1854:OTEOST >2.0.CO;2.

IPCC, 2013: Summary for policymakers. Climate Change 2013: The Physical Science Basis, T. F. Stocker et al., Eds., Cambridge University Press, 3-29.

Ivancic, T. J., and S. B. Shaw, 2016: A U.S.-based analysis of the ability of the Clausius-Clapeyron relationship to explain changes in extreme rainfall with changing temperature. J. Geophys. Res. Atmos., 121, 3066-3078, doi:10.1002/2015JD024288.

Janssen, E., D. J. Wuebbles, K. E. Kunkel, S. C. Olsen, and A. Goodman, 2014: Observational- and model-based trends and projections of extreme precipitation over the contiguous United States. Earth's Future, 2, 99-113, doi:10.1002/2013EF000185.

Knight, J. R., C. K. Folland, and A. A. Scaife, 2006: Climate impacts of the Atlantic multidecadal oscillation. Geophys. Res. Lett., 33, L17706, doi:10.1029/2006GL026242.

Konrad, C. E., II, 2001: The most extreme precipitation events over the eastern United States from 1950 to 1996: Considerations of scale. J. Hydrometeor., 2, 309-325, doi:10.1175/ 1525-7541(2001)002<0309:TMEPEO>2.0.CO;2.
Kunkel, K. E., D. R. Easterling, D. A. R. Kristovich, B. Gleason, L. Stoecker, and R. Smith, 2012: Meteorological causes of the secular variations in observed extreme precipitation events for the conterminous United States. J. Hydrometeor., 13, 11311141, doi:10.1175/JHM-D-11-0108.1.

and Coauthors, 2013: Regional climate trends and scenarios for the U.S. National Climate Assessment: Part 1. Climate of the Northeast U.S. NOAA Tech. Rep. NESDIS 142-1, 87 pp. [Available online at https://scenarios.globalchange.gov/sites/ default/files/NOAA_NESDIS_Tech_Report_142-1-Climate_ of_the_Northeast_U.S_1.pdf.]

McCarty, W., L. Coy, R. Gelaro, A. Huang, D. Merkova, E. B. Smith, M. Seinkiewicz, and K. Wargan, 2016: MERRA-2 input observations: Summary and assessment. NASA Tech. Rep. Series on Global Modeling and Data Assimilation, NASA/ TM-2016-104606, 61 pp. [Available online at https://gmao. gsfc.nasa.gov/pubs/docs/McCarty885.pdf.]

Melillo, J. M., T. C. Richmond, and G. W. Yohe, 2014: Our changing climate. Climate Change Impacts in the United States: The Third National Climate Assessment, J. M. Melillo, T. C. Richmond, and G. W. Yohe, Eds., U.S. Global Change Research Program, 19-67, doi:10.7930/J0KW5CXT.

Molod, A., L. Takacs, M. Suarez, and J. Bacmeister, 2015: Development of the GEOS-5 atmospheric general circulation model: Evolution from MERRA to MERRA2. Geosci. Model Dev., 8, 1339-1356, doi:10.5194/gmd-8-1339-2015.

Pook, M. J., P. C. McIntosh, and G. A. Meyers, 2006: The synoptic decomposition of cool-season rainfall in the southeastern Australian cropping region. J. Appl. Meteor. Climatol., 45, 1156-1170, doi:10.1175/JAM2394.1.

Reichle, R. H., and Q. Liu, 2014: Observation-corrected precipitation estimates in GEOS-5. NASA Tech. Memo. NASA/ TM-2014-104606/Vol. 35, 24 pp. [Available online at https:// gmao.gsfc.nasa.gov/pubs/docs/Reichle734.pdf.]

Rienecker, M. M., and Coauthors, 2011: MERRA, NASA's Modern-Era Retrospective Analysis for Research and Applications. J. Climate, 24, 3624-3648, doi:10.1175/ JCLI-D-11-00015.1.

Risbey, J. S., P. C. McIntosh, and M. J. Pook, 2013: Synoptic components of rainfall variability and trends in southeast Australia. Int. J. Climatol., 33, 2459-2472, doi:10.1002/joc.3597.

Rivera, E. R., F. Dominguez, and C. L. Castro, 2014: Atmospheric rivers and cool season extreme precipitation events in the Verde River basin of Arizona. J. Hydrometeor., 15, 813-829, doi:10.1175/JHM-D-12-0189.1.

Stadtherr, L., D. Coumou, V. Petoukhov, S. Petri, and S. Rahmstorf, 2016: Record Balkan floods of 2014 linked to planetary wave resonance. Sci. Adv., 2, e1501428, doi:10.1126/sciadv.1501428.

Takacs, L. L., M. J. Suárez, and R. Todling, 2016: Maintaining atmospheric mass and water balance in reanalyses. Quart. J. Roy. Meteor. Soc., 142, 1565-1573, doi:10.1002/qj.2763.

Warner, M. D., C. F. Mass, and E. P. Salathé Jr., 2012: Wintertime extreme precipitation events along the Pacific Northwest coast: Climatology and synoptic evolution. Mon. Wea. Rev., 140, 2021-2043, doi:10.1175/MWR-D-11-00197.1.

Westby, R. M., and R. X. Black, 2015: Development of anomalous temperature regimes over the southeastern United States: Synoptic behavior and role of low-frequency modes. Wea. Forecasting, 30, 553-570, doi:10.1175/WAF-D-14-00093.1.

Xie, P., A. Yatagai, M. Chen, T. Hayasaka, Y. Fukushima, C. Liu, and S. Yang, 2007: A gauge-based analysis of daily precipitation over East Asia. J. Hydrometeor., 8, 607-626, doi:10.1175/ JHM583.1. 